\title{
Investigating the effectiveness of a fish- protection structure of the reclamation water intake
}

\author{
Svetlana Dragunova ${ }^{1}$,Evgeny Kuznetsov ${ }^{1}$, Anna Khadzhidi $^{1}$, Alexander Koltsov ${ }^{2,}$, and \\ Noureldin Sharaby ${ }^{2,3}$ \\ ${ }^{1}$ Kuban State Agrarian University named after I.T. Trubilina, 350044, 13, Kalinina str, Krasnodar, \\ Russia \\ ${ }^{2}$ Don State Technical University, 344003, Gagarin sq., 1, Rostov-on-Don, Russia \\ ${ }^{3}$ Agricultural Engineering Department, 33516, Faculty of Agriculture, Kafrelsheikh University, El- \\ Geish Street, Egypt
}

\begin{abstract}
The study was conducted at the reclamation water intake facility of Tikhovsky hydroelectric complex. We used data from long-term observations and results of laboratory studies on a 1:20 scale physical model of the Zapan fish protection device. The effectiveness of the model was evaluated using simulators of juvenile fish. Increasing the efficiency of the Zapan fish protection facility is achieved by additional placement in the bottom threshold, which directs the bottom flow along with the young fish to the springboard, where there is an airlift in the form of a bubble curtain that lifts the young along the springboard into the fish-receiving holes of permeable shields. Fish protection design and location in the middle of the water stream do not create a backwater due to low resistance and provide protection for young fish. This increases not only the survival rate of young fish, but also the efficiency of reclamation water intakes. A new design of a fish protection structure for reclamation water intakes of the Zapan type was developed, which provides a fish protection effect of 3 groups of young fish formed by their swimming ability, which allowed determining the size of the elements of the fish protection structure.
\end{abstract}

\section{Introduction}

In modern conditions, biological resources are gradually degrading. This is due to the management of runoff, improper use of water resources, unsatisfactory operation of reclamation and hydraulic structures [1-2]. Reclamation water intakes are insufficiently equipped with fish protection devices; therefore, it is necessary to develop and improve fish protection devices [3]. One of the largest consumers of water is rice and irrigation systems, which are equipped with fish protection devices [3]. At the beginning of the XXI century, the reclamation water intake of the Petrovsko-Anastasievskaya irrigation system was put into operation as part of the Tikhovsky water-sharing hydroelectric comlex on the Kuban

\footnotetext{
*Corresponding author coltsov.sanya@yandex.ru
} 
river, Kuban [4]. The Petrovsko-Anastasievskaya irrigation system is one of the largest consumers of water for rice irrigation systems in the Krasnodar Territory. The project of fish protection structures (hereinafter RZS) for the PAOS was carried out at the end of the 20th century, and the reclamation water intake was put into operation in 2006 [4]. The operation of the water intake has shown that protection efficiency does not exceed $60 \%$. This indicator of the efficiency of the RZS does not meet the environmental standards on the river of the highest category of biological resources, where the indicator of juvenile fish protection should be above $70 \%$ [5].

\section{Materials and methods}

The studies were carried out at the reclamation water intake structure of the PAOS as part of the Tikhovsky hydroelectric complex during the growing season of rice in 2014-19. Data from long-term field observations were used. Laboratory studies were carried out on a 1:20 scale physical model of the damper, which is installed in the hydraulic tray. Experimental samples were used as simulators of juvenile fish, which could be located on the surface, in the stream and at the bottom of the tray. In total, 3 groups of simulators of 300 pieces were studied. in each, the groups were different in color. A comprehensive assessment of the effectiveness of protection by the sealing elements of each group of simulators was carried out. The Froude number was in the range $-0.1-0.08$, with a flow depth of $0.2-0.5 \mathrm{~m}$ in the tray. 5 experiments were performed in 5 repetitions. Experimental data processing was carried out by known methods of mathematical analysis.

\section{Results}

The consumption (intake) of water for irrigation of PAOS rice is shown in the graph (Figure 1), where $\mathrm{Q}$ is the water consumption $\left(\mathrm{m}^{3} / \mathrm{s}\right)$.

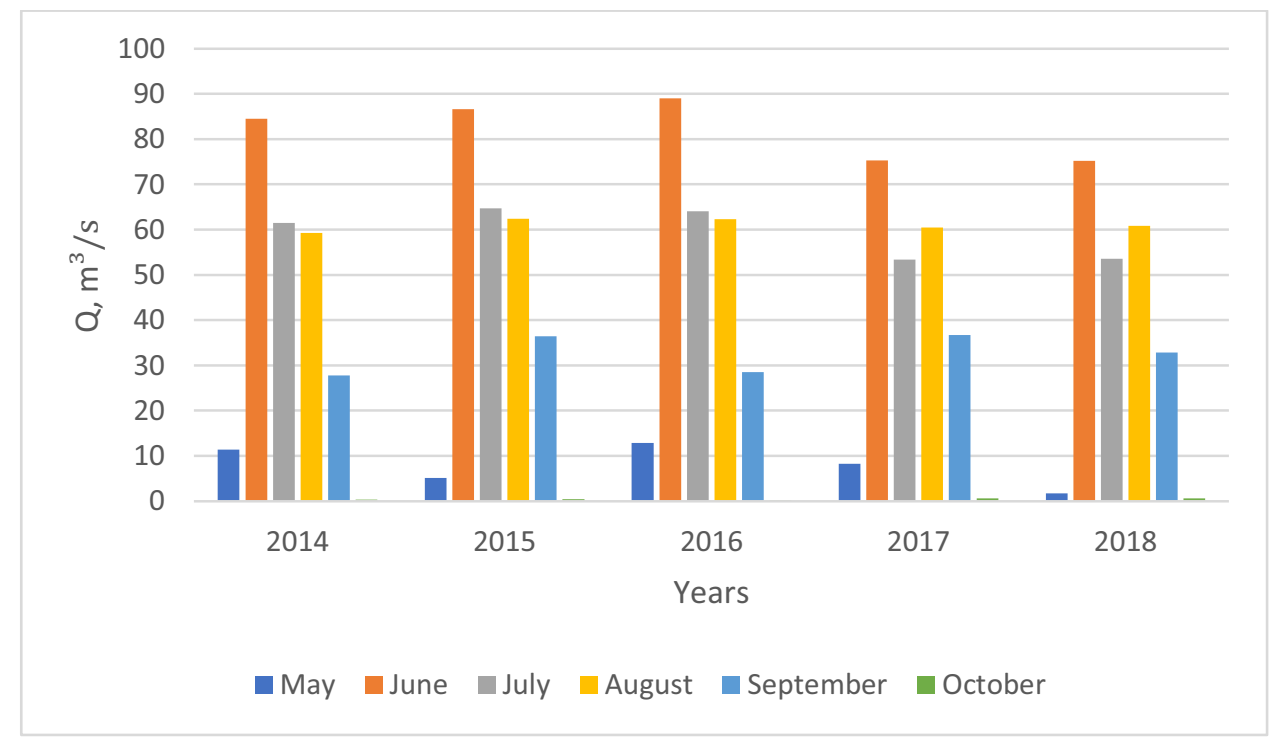

Fig. 1. Diagram of water intake from the Kuban river to the PAOS

Analysis of water consumption over 5 years shows that the maximum volumes of water intake into the system are observed in June when rice paddies are flooded intensively, as well as the maximum peak in the downstream migration of young fish along the river. 
Water withdrawals reach $90 \mathrm{~m} 3 / \mathrm{s}$ and during this time of the year, there is also an active spawning of fish. It is necessary to protect young fish from death during this period [6].

In the Krasnodar Territory, there is a growing trend for increasing the proportion of rice in the crop rotation, and, consequently, the volume of water for rice cultivation will increase. The increase in water volumes will affect the operation of reclamation water intakes, because they will need to be modernized to increase the efficiency of protection of young fish, and, especially, this applies to the reclamation water intake of the PAOS. Therefore, the design of the reclamation water intake should be improved to ensure more effective protection of juvenile fish with increased water intake into the irrigation system.

The combined design of the RZS "Zapan" makes it possible to increase the efficiency of juvenile fish protection from entering the water intake structure. The diagrams (Figures 2 and 3) show the RZS "Zapan", which is sequential, i.e. systematically protects juveniles from entering the irrigation system.

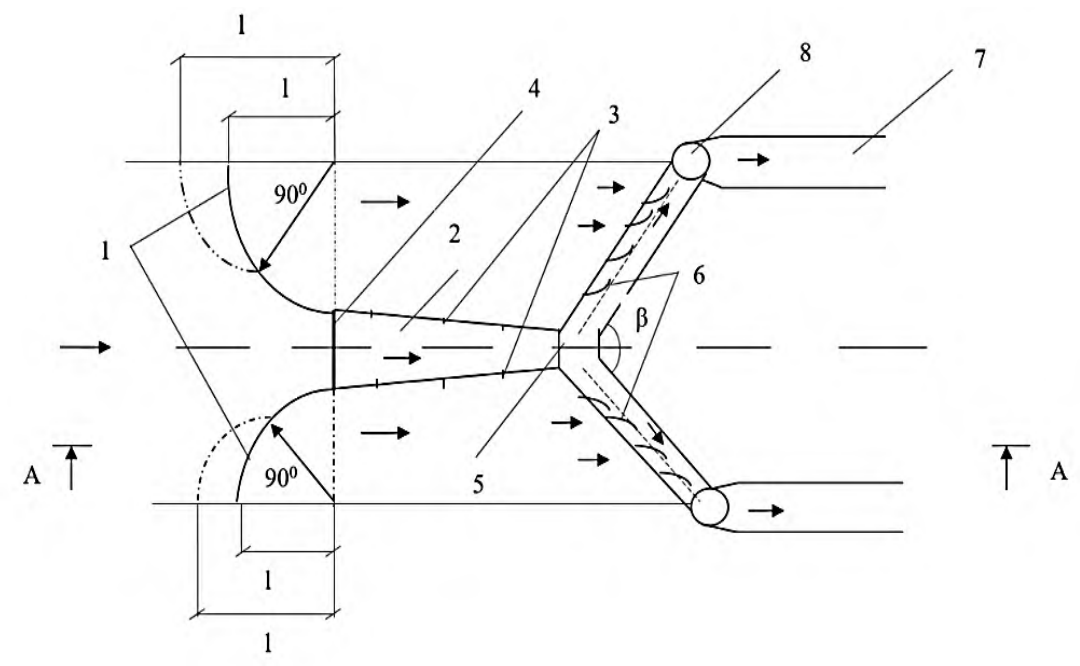

1 - curvilinear bottom threshold; 2 - fish-lifting springboard; 3 - branch pipes; 4 - fishcatching head;

5 - zapan; 6 - fish catching windows; 7- fish trays; 8 - fish receiving chamber; 1 - design parameter; $\beta$ is the expansion angle of the zapan; $\rightarrow$ - the direction of movement of young fish simulators

Fig. 2. Fish protection structure "Zapan" combined design 


\section{A-A}

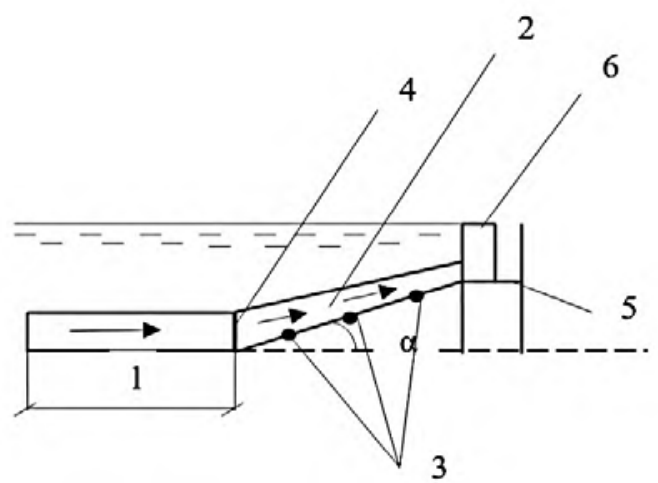

1 - curvilinear bottom threshold; 2 - fish-lifting springboard; 3 - branch pipes; 4 - fishcatching head;

5 - zapan; 6 - fish catching windows; 1 - design parameter; $\alpha$ is the slope of the springboard;

$\rightarrow$ - the direction of movement of young fish simulators

Fig. 3. Section of the fish protection structure along the springboard axis

The fish protection structure "Zapan" (Figures 2 and 3) has a curvilinear bottom threshold 1 with a height of at least $3 / 4$ of the depth of the water flow, with a fish-lifting springboard 2, equipped with perforated pipes 3 to provide an airlift. The fish-lifting springboard is made in the form of a truncated cone and is connected by a smaller base with a zapan, which is provided with additional fish-collecting trays 7 symmetrically located relative to the axis of the water flow, installed to each other in a horizontal plane at an angle of $75-90^{\circ}$ and equipped with fish-receiving chambers 8 located in front of the fishcollecting trays.

For more efficient use of water flow energy on the springboard, compressed air is supplied from a perforated pipeline. The fish-lifting springboard is installed at an angle $\alpha$ equal to $20-30^{\circ}$ between the bottom fish-catching head and the zapan 5 . The zapan is made from a fish-removal tray with a horizontal shelf, a vertical blind back wall and a vertical front wall with curvilinear gaps in the form of fish-catching windows 6. Zapan fish trays are arranged at an angle $\beta$, which is adjusted according to the results of the best protection efficiency for juvenile fish. Equipping curvilinear windows, which are made in the form of an arc with a rounding angle of $10-130^{\circ}$, allows you to catch more than $70 \%$ of juvenile fish and contributes to the smooth flow of water flow onto the shelf into the transit stream, which runs parallel to the rear wall of the shelf, thereby increasing the fish-protecting effect without damaging the juveniles and taking her to a safe place.

To improve the protection efficiency of juvenile fish, the windows are installed at an angle of $45^{\circ}$ and are located between the fish chute and the fish-lifting springboard, and the fish receiving chamber.

RZS works as follows. Juveniles enter the device through a curvilinear bottom threshold, then enters through the fish-catching head into a fish-lifting springboard, made in the form of a truncated cone, into which compressed air is supplied through the pipes, located on the springboard at distances of $1 / 3$ to ensure the effective operation of the fish protection device. When air is supplied, a water-air mass is formed, which creates a stepped rise along the length of the springboard, without injuring the young fish. On the fish-lifting springboard, juvenile fish move up to the zapan shelf. Fish-catching windows capture 
juveniles, then, parallel to the rear wall of the shelf, the juveniles are taken to a safe place by water flow through the fish receiving chamber and the fish chute.

To confirm the efficiency of the reclamation water intake from the RZS «Zapan», experiments were carried out on a model at a scale of 1:20, which is shown in the diagram (Figure 2). In the course of the study, the fish-protective effect of the combined design of the RZS for simulators of 3 groups of juvenile fish was established, which exceeded $74 \%$.

The RZS "Zapan" provides fish protection efficiency for young fish of more than $70 \%$. This fish protection structure is complex. It's supposed location - in the middle of the water flow, ensures the capture of the migrating juvenile fish, regardless of their accumulation at one or another coast in the supply channel of the PAOS reclamation water intake. This increases the survival rate of juvenile fish. The operation of the developed complex RZS will ensure the capture of juvenile fish throughout the entire living section of the watercourse, which will further increase its efficiency.

Zapan of the combined structure is lowered under the level to the required depth of water-permeable shields, fixed to the supporting structure. The depth of the shields should not exceed a third of the flow depth. To improve fish drainage, the structure is installed at an angle to the incoming stream and is supplied with a horizontal shelf. A capturing stream is formed along the upper-pressure edge, which transports the young along the entire device to the fish outlet and then to the discharge channel.

\section{Conclusion}

A new design of the fish protection structure of reclamation water intakes of the "Zapan" type has been developed, which provides the fish protection effect of 3 groups of juvenile fish, which were formed according to their swimming ability, this made it possible to establish the dimensions of the RZS elements.

The results of the research on a physical model, taking into account the water consumption for the PAOS, show an increase in the efficiency of fish protection structures of reclamation water intakes of the Zapan type by more than $74 \%$.

\section{References}

1. F. Al-Faraj, M. Scholz, Impact of upstream anthropogenic river regulation on downstream water availability in transboundary river watersheds. Int J Water Resour D 31(1), 28-49 (2014) DOI:10.1080/07900 627.2014.92439 531

2. A. A. Kouchak, A. Farahmand, F. S. Melton, J. Teixeira, M. C. Anderson, B. D. Wardlow, C. R. Hain Remote sensing of drought: Progress, challenges, and opportunities. Rev Geophys, 53(2), 452-480 (2015) DOI:10.1002/2014RG000456

3. Ya. V. Kuz'menko, F. N. Lisetskii, Zh. A. Kirilenko, O. I. Grigor'eva, “Provision of Optimum Water Protection Forest Coverage in Case of Basin Organization of Nature Management," 3, 15 (2013)

4. Ya. V. Kuz'menko, F. N. Lisetskii, A. G. Narozhnyaya, "Using the Basic Concept of Nature Management for Soil and Water Protection Development of Agricultural Landscapes", 1, 14 (2012)

5. Ya. V. Kuz'menko, F. N. Lisetskii, V. I. Pichura, "Evaluation and Prediction of Flow of Small Rivers in Anthropogenic Impacts and Climate Change" Modern Problems of Science and Education, 6 (2012) 
6. F. N. Lisetskii, Zh. A. Kirilenko, Ya. V. Kuz'menko, O. A. Marinina, "Monitoring of Surface and Underground Water in Case of Basin Organization of Nature Management. Database State Registration Certificate No. 2013621378, 4 (2013)

7. F. N. Lisetskii, A. G. Panin, Basic Concept of Nature Management on Rural Territories in the Belgorod Oblast, 1 (2013)

8. T. I. Moiseenko, A. V. Soromotin, A. D. Shalabodov, "Water Quality and Pollution Normalization Method", 7 (2010)

9. F. N. Lisetskii, Basin organization of nature management for solving hydroecological problems, J Russian Meteorology and Hydrology, 39(8), 550-557 (2014) DOI: 10.3103/S106837391408007X

10. V. N. Shchedrin, Meliorative institutional environment: The area of state interests, Espacios, 39(12), 28 (2018)

11. A. Lee, S. Cho, DK. Kang, S. Kim Analysis of the effect of cli-mate change on the Nakdong river stream flow using indicators of hydrological alteration. J Hydro-environ Res 8(3), 234-247 (2014) DOI: 10.1016/j.jher.2013.09.003

12. I. Masih, S. Uhlenbrook, M. D. Ahmad, S. Maskey, Regionaliza-tion of a conceptual rainfall runoff model based on similarity of the flow duration curve: a case study from Karkheh River Basin, Iran. J Hydrol, 391(1-2), 188-201 (2010) DOI: 10.1016/j.jhydrol.2010.07.018

13. R. Mohammed, M. Scholz, M. Zounemat-Kermani. Tempo-ral hydrologic alterations coupled with climate variability and drought for transboundary river basins. Water Resour Manage, 31, 1489-1502 (2017) DOI: 10.1007/s11269-017-1590-0

14. J. Reis, T. B. Culver, P. J. Block, M. P. McCartney, Evaluating the impact and uncertainty of reservoir operation for malaria control as the climate changes in Ethiopia. Clim Chang, 136(3-4), 601-614 (2016) DOI: 10.1007/s10584-016-1639-8

15. Y. Saeedrashed, A. Guven, Estimation of geomorphologi-cal parameters of Lower Zab River-Basin by using GIS-based remotely sensed image. Water Resour Manage, 27, 209-219 (2017) DOI:10.1007/s1126 9-012-0179-x 